\title{
Screening of Von Willebrand Disease in Iranian Women With Menorrhagia
}

\author{
Nahid Rahbar ${ }^{1}$; Mohammad Faranoush ${ }^{2, *}$; Raheb Ghorbani ${ }^{3}$; Bahare Sadr Alsadat $^{1}$ \\ ${ }^{1}$ Research center of Abnormal Uterine Bleeding, Semnan University of Medical Science, Semnan, IR Iran \\ ${ }_{2}^{1}$ Research center of Abnormal Uterine Bleeding, Semnan University of Medical Scien
${ }_{3}^{2}$ Hazrat Rasool Akram Hospital, Iran University of Medical Sciences, Tehran, IR Iran \\ ${ }^{3}$ Research Center for Social Determinants of Health, Department of Community Medicine, Faculty of Medicine, Semnan University of Medical Sciences, Semnan, IR Iran \\ ${ }^{*}$ Corresponding Author: Mohammad Faranoush, Hazrat Rasool Akram Hospital, Iran University of Medical Sciences, Tehran, IR Iran. Tel: +98-2188212106, Fax: +98-2188601580, \\ E-mail: faranoush47@gmail.com \\ Received: February 15, 2014; Revised: November 12, 2014; Accepted: December 6, 2014
}

\begin{abstract}
Background: Menorrhagia is a common health problem in women, particularly those with bleeding disorders. Little is known about the course of menorrhagia or other bleeding symptoms in women with the most common congenital bleeding disorder, von Willebrand disease (vWD).

Objectives: The aim of this study was to estimate the prevalence of vWD in women with diagnosed menorrhagia.

Materials and Methods: In this cross-sectional study, a total of 460 consecutive patients, presenting menorrhagia, were analyzed. The initial screening and confirmation tests for the diagnosis of vWDincluded determination of prothrombin time(PT), partial thromboplastin time (PTT), bleeding time (BT), fibrinogen, factor VIII, vWF antigen, and vWF activity. A questionnaire was filled for every patient. The data were then analyzed using the SPSS software.

Results: Mean age of our patients was $32.5 \pm 10.6$ years. The level of von Willebrand factor in $22.5 \%$ and von Willebrand activity in $19.6 \%$ of patients was abnormal. The prevalence of vWD among patients with menorrhagia was $24 \%$.

Conclusions: The high prevalence of vWD among our patients was the same as other previous reports, suggesting low awareness about this disease and under diagnosis of mild cases.
\end{abstract}

Keywords:Menorrhagia; Von Willebrand Disease; Von Willebrand Factor

\section{Background}

Von Willebrand disease (vWD) is the most common inherited bleeding disorder, resulting from a quantitative or qualitative deficiency of von Willebrand factor (VWF), with prevalence of up to $1.3 \%$ in the general population (1-7). This disease is considered as an iceberg (3). The disease could range from mild to severe, typically with easy bruising or mucocutaneous bleeding (39). The severe form of disease is usually diagnosed due to more clinical signs and symptoms (7-12). Both sexes are equally affected with to the disease's autosomal inheritance pattern, yet there is a higher frequency of symptoms in women due menorrhagia and pregnancy complications (11-16). Some guidelines suggest that screening for vWD in women with heavy menses or iron deficiency anemia, abnormal bleeding during or after delivery of child, passing clots with more than 1 inch in diameter and or more than 1 pad per hour. Menorrhagia is abnormal heavy and prolonged menses, a common complaint during reproductive age in women (1). The causes of menorrhagia include gynecologic, endocrine and hepatic disorders, trauma and hemostatic disorders, yet multifactorial causes are found in many cases. Unfortunately in more than $50 \%$ of cases with menorrhagia the physician doesn't find the underlying disease (14-20). Many women with menorrhagia and heavy menses may have under diagnosed vWD disease due to a lack of referral for coagulation tests (19-24). Menorrhagia causes a decrease in quality of life, social awareness, fatigue, anemia and sexual problems (1, 2227). Several studies have reported a vWD frequency of $5 \%$ to $20 \%$ in women with menorrhagia (1-6). Proper diagnosis and treatment can reduce side effects and inappropriate surgical interventions (6).

\section{Objectives}

This study was performed to survey adolescent and adult females with menorrhagia for vWD.

\section{Materials and Methods}

In this cross-sectional study, conducted from 2009 to 2012, 460 patients with menorrhagia referred to AmirAlmomenin hospital (an academic hospital under the authority of Semnan University of Medical Sciences, Semnan, Iran) and then to the Comprehensive Hemophilia Care Center (CHCC) in Tehran were assessed. The study design was approved by the ethical committee of Semnan University of Medical Sciences. Amongst all candidates, 52 patients were referred for testing and were excluded from the study. Finally 408 patients were

Copyright (C) 2015, Iranian Red Crescent Medical Journal. This is an open-access article distributed under the terms of the Creative Commons Attribution-NonCommercial 4.0 International License (http://creativecommons.org/licenses/by-nc/4.0/) which permits copy and redistribute the material just in noncommercial usages, provided the original work is properly cited. 
included in the study. Regarding the prevalence of $12.3 \%$ for von Willebrand in patients with menorrhagia based on the study by Stefanska and colleagues (28), and to achieve a 95\% confidence interval and accuracy of $3.2 \%$, sample size was estimated as 408 by the following formula:

$$
\mathrm{n}=\left(\mathrm{Z}_{1-\alpha / 2}^{2} \mathrm{P}(1-\mathrm{P})\right) / \mathrm{d}^{2}
$$

Menorrhagia was diagnosed based on the patient's history and amount of menstrual bleeding while the number of used pads per day by the patient was measured based on bleeding scores (29). Inclusion criteria were defined as having bleeding that lasted for more than seven days or resulted in a loss of more than 80 $\mathrm{mL}$ of blood per menstrual cycle, being an adolescent with menorrhagia, adult female with menorrhagia without any other cause or female undergoing a hysterectomy for menorrhagia. Menorrhagia was not related to hormonal disorders, renal or hepatic disease. All patients who received hormonal, antifibrinolytic or antibiotic drugs must have referred at one month after abstinence. All patients, their parents or legal guardians signed an informed consent. The epidemiological data were assessed by a questionnaire including the patient's name, age, marriage and parity status, pelvic ultrasound result, history of endometriosis, history of systemic disease including anemia, liver or renal disease, ovarian cyst or fibroma. The pads used by the patients during each day were collected. The patients were interviewed by obstetricians and gynecology residents, and in a reference laboratory a 10 cc blood sample was drawn (stored in EDTA) from each patient for coagulation tests including: complete blood count (CBC), platelet, prothrombin time (PT), partial thromboplastin time (PTT), bleeding time, fibrinogen, factor VIII, factor XIII, vW antigen, vW antigen activity, on day nine to 14 of the menstrual cycle. Von Willebrand factor was measured by a diagnostic kit from Stago (France) and or Technoplan (Austria) company. A test was considered abnormal if its second result was below the standard. All cases were examined by sonography for detection of ovarian cysts and uterine fibroma. Data were analyzed by the SPSS 16.00 software. We used chisquare test for data analysis. $\mathrm{P}<0.05$ was considered statistically significant.

\section{Results}

We included 408 women with menorrhagia. vWD was diagnosed in $24 \%$ of patients. Mean \pm SD of age was 32.5 \pm 10.6 years (median $=33.5$, range $13-49$ years). Most patients were diagnosed at the age of 31 to 40 years (34.3\%). The level of VWF antigen activity had a significant relationship with age (Table 1). Sonography results indicated cysts in $2.2 \%$ of cases, fibroma in $15.9 \%$ and normal findings in $81.9 \%$ (Table 1). In this study, there was an abnormal level of fibrinogen in nine cases (2.2\%), factor VIII in 40 cases (9.8\%), von Willebrand factor antigen in 92 cases (22.5\%) and von Willebrand factor activity in 80 cases (19.6\%). History of abortion was found in $16.9 \%$ of cases, history of ovarian cyst in $16.7 \%$, history of fibroma in $16.9 \%$ and history of systemic disease was observed in $44.9 \%$ of cases (Tables 1 and 2). Frequency of patients' parity and bleeding during menstruation is shown in Table 2 . Overall, $43 \%$ of patients with a history of menorrhagia had no other symptoms. The frequencies of other symptoms were as follows, epistaxis $67.6 \%$, ecchymosis $51.4 \%$, and other bleeding symptoms $41.7 \%$ in the remainder of patients. In our study, decrease vWF activity related by fibroma is significant $(P=0.001)$ in compare to vWF antigen $(\mathrm{P}=0.212)$. The relationship between age and von Willebrand factor level $(P=0.003)$ and von Willebrand factor activity $(\mathrm{P}=0.02)$ was statistically significant. The results showed that the prevalence of vWD disease in those less than 40 years of age was greater than patients over 40 .

Table 1. Frequency of Von Willebrand Factor Antigen and Activity Based on Age and Pelvic Ultrasound Findings of Patients with Menorrhagia $^{\text {a }}$

\begin{tabular}{|c|c|c|c|c|c|}
\hline & \multirow[t]{2}{*}{ Patients, No. } & \multicolumn{2}{|c|}{ Level of von Willebrand Factor } & \multicolumn{2}{|c|}{ von Willebrand Activity } \\
\hline & & Abnormal & PValue & Abnormal & PValue \\
\hline Age, $y$ & & & 0.003 & & 0.020 \\
\hline$\leq 20$ & 74 & $24(32.4)$ & & $15(20.3)$ & \\
\hline $21-30$ & 86 & $25(29.1)$ & & $16(18.6)$ & \\
\hline $31-40$ & 140 & $18(12.9)$ & & $18(12.9)$ & \\
\hline$>40$ & 108 & $25(23.1)$ & & $31(28.7)$ & \\
\hline Sonography findings & & & 0.212 & & 0.001 \\
\hline Normal & 334 & $75(22.5)$ & & $57(17.1)$ & \\
\hline Fibroma & 65 & $17(26.2)$ & & $23(35.4)$ & \\
\hline Ovarian Cyst & 9 & - & & - & \\
\hline
\end{tabular}




\begin{tabular}{lc}
\hline \multicolumn{2}{l}{ Table 2. Characteristics of Patients with Menorrhagia } \\
\hline Characteristic & No. (\%) \\
\hline Parity & $69(16.9)$ \\
\hline 0 & $129(31.6)$ \\
\hline 1 & $125(30.6)$ \\
\hline 2 & $85(20.9)$ \\
\hline$\geq 3$ & $69(16.9)$ \\
\hline Abortion & $68(16.7)$ \\
\hline History of ovarian cyst & $69(16.9)$ \\
\hline History of fibroma & \\
\hline History of systemic disease & $225(55.1)$ \\
\hline None & $137(33.6)$ \\
\hline anemia & $35(8.6)$ \\
\hline thyroid disease & $3(0.7)$ \\
\hline liver disease & $8(2.0)$ \\
\hline others & \\
\hline Volume of bleeding & $35(8.6)$ \\
\hline low & $191(46.8)$ \\
\hline Intermediate & $182(44.6)$ \\
\hline Massive & $264(64.7)$ \\
\hline Llot excrete & $144(35.3)$ \\
\hline Intermediate or massive & \\
\hline
\end{tabular}

\section{Discussion}

Our results showed that von Willebrand factor level in $22.5 \%$ of patients and von Willebrand factor activity in $19.6 \%$ of patients was abnormal, and the prevalence of vWD in patients with menorrhagia was $24 \%$. Some reports have shown that the severity of symptoms don't relate to the blood level of coagulation factor in some inherited diseases $(30,31)$. Dilley and colleague assessed vWD and other inherited bleeding disorders in women with menorrhagia. The study included 121 women with menorrhagia and 123 controls and showed that bleeding disorders (vWD, factor deficiency, or a platelet abnormality) were diagnosed in $10.7 \%$ of patients with menorrhagia and $3.2 \%$ of controls $(P=0.02)$. vWD was present in eight patients with menorrhagia (6.6\%) and in one control $(0.8 \%)(P=0.02)(7,8)$. Saxena reported on inherited bleeding disorders in Indian women with menorrhagia. A total of 337 from 2200 women with menorrhagia were found to have an inherited bleeding disorder, 221 of these 337 women had menorrhagia alone while 116 also had other associated bleeding manifestations such as prolonged bleeding from the injury site, ecchymotic patches on the skin, epistaxis and hemarthrosis. They found that vWD was the most frequent disease amongst the 40 (11.9\%) studied cases, yet the frequency was less than what was found by our study (10).
Some studies have reported the lowest vWF level during the first half of the menstrual cycle. We designed our study according to these reports $(3,11)$. Chen and colleagues studied the prevalence of VWD in women with iron deficiency anemia and menorrhagia was evaluated by patients' menses history. Both von Willebrand factor antigen (VWF: Ag) and ristocetin activity (VWF: RCO) were measured for each patient. The diagnosis was established if both vWF $<50 \%$ and vWF: RCO $<50 \%$ were present. Nine of the $56(16.1 \%)$ patients were identified to have vWD, which was similar to the result of our study (15). In this study, we evaluated vWF level and vWF activity based on the patient's age. Our results showed that the number of patients with abnormal levels of VWF at a younger age was higher and this difference was statistically significant $(P=0.02)$. The other studies showed that menorrhagia after 40 years is considered as a gynecologic problem such as anovulatory cycles (2, 7-13). We also found that $2.2 \%$ of patients with menorrhagia had abnormal levels of fibrinogen and 9.8\% had abnormal mild deficiency of factor VIII, so it is important to consider these factors in patients' coagulation screening. The patients with abnormal factor VIII deficiency may be considered as carriers (5-11). We found a significant relationship between fibroma and VWF activity ( $P$ $=0.001$ ). Some studies showed a relationship between abnormal anatomical findings and VWD. In one study, $50 \%$ of women with vWD after hysterectomy had anatomical uterine pathology $(5,13,17,19)$. Proper and right diagnosis of patients with menorrhagia for VWD has many advantages for improving health related quality of life for the patients, and make an attention for surgery with caution on bleeding tendency. It is useful for detection of disease in close family with minor bleeding symptoms.(1, 9, 10, 25). In conclusion, awareness of abnormal menstrual bleeding amongst physician and midwives leads to early diagnosis, improves quality of life and decreases anemia. Multidisciplinary approach is required to diagnose and treat patients with menorrhagia amongst hematologists and gynecologists. This Iranian study was the first of its kind yet we did not consider some important data for example blood group, so it is recommended for future studies to have larger sample sizes from multiple health centers and evaluate more variables.

\section{Acknowledgements}

We acknowledge and thank the kind cooperation of the personnel at the Iranian Hemophilia Care center especially Mr. Chupan.

\section{Authors' Contributions}

Mohammad Faranoush: hematological consult and supervision. Raheb Ghorbani: statistical consult and data analysis. Zahra Sadr: collection of data and literature review. Nahid Rahbar: project manager and paper writing. 


\section{References}

1. Sweet MG, Schmidt-Dalton TA, Weiss PM, Madsen KP. Evaluation and management of abnormal uterine bleeding in premenopausal women. Am Fam Physician. 2012;85(1):35-43.

2. Warner PE, Critchley HO, Lumsden MA, Campbell-Brown M, Douglas A, Murray GD. Menorrhagia I: measured blood loss, clinical features, and outcome in women with heavy periods: a survey with follow-up data. Am J Obstet Gynecol. 2004;190(5):1216-23.

3. Kujovich JL. von Willebrand's disease and menorrhagia: prevalence, diagnosis, and management. Am J Hematol. 2005;79(3):220-8.

4. James AH. More than menorrhagia: a review of the obstetric and gynaecological manifestations of bleeding disorders. Haemophilia. 2005;11(4):295-307.

5. Philipp CS, Faiz A, Dowling N, Dilley A, Michaels LA, Ayers C, et al. Age and the prevalence of bleeding disorders in women with menorrhagia. Obstet Gynecol. 2005;105(1):61-6.

6. Pacheco LD, Costantine MM, Saade GR, Mucowski S, Hankins GD Sciscione AC. von Willebrand disease and pregnancy: a practical approach for the diagnosis and treatment. Am J Obstet Gynecol. 2010;203(3):194-200.

7. Dilley A, Drews C, Miller C, Lally C, Austin H, Ramaswamy D, et al. von Willebrand disease and other inherited bleeding disorders in women with diagnosed menorrhagia. Obstet Gynecol. 2001;97(4):630-6.

8. Dilley A, Drews C, Lally C, Austin H, Barnhart E, Evatt B. A survey of gynecologists concerning menorrhagia: perceptions of bleeding disorders as a possible cause. $J$ Womens Health Gend Based Med. 2002;11(1):39-44.

9. Shankar M, Lee CA, Sabin CA, Economides DL, Kadir RA. von Willebrand disease in women with menorrhagia: a systematic review. BJOG. 2004;111(7):734-40.

10. Saxena R, Gupta M, Gupta PK, Kashyap R, Choudhry VP, Bhargava $M$. Inherited bleeding disorders in Indian women with menorrhagia. Haemophilia. 2003;9(2):193-6.

11. Federici AB, Berntorp E, Lee CA. The 80th anniversary of von Willebrand's disease: history, management and research. Haemophilia. 2006;12(6):563-72.

12. Warner P, Critchley HO, Lumsden MA, Campbell-Brown M, Douglas A, Murray G. Referral for menstrual problems: cross sectional survey of symptoms, reasons for referral, and management. BMJ. 2001;323(7303):24-8.

13. Goodman-Gruen D, Hollenbach K. The Prevalence of von Willebrand disease in women with abnormal uterine bleeding. $J$ Womens Health Gend Based Med. 2001;10(7):677-80.

14. Philipp CS, Dilley A, Miller CH, Evatt B, Baranwal A, Schwartz R, et al. Platelet functional defects in women with unexplained menorrhagia. J Thromb Haemost. 2003;1(3):477-84.

15. Chen YC, Chao TY, Cheng SN, Hu SH, Liu JY. Prevalence of von Willebrand disease in women with iron deficiency anaemia and menorrhagia in Taiwan. Haemophilia. 2008;14(4):768-74

16. Woo YL, White B, Corbally R, Byrne M, O'Connell N, O'Shea E, et al von Willebrand's disease: an important cause of dysfunctional uterine bleeding. Blood Coagul Fibrinolysis. 2002;13(2):89-93.

17. Lukes AS, Kouides PA. Hysterectomy versus expanded medica treatment for abnormal uterine bleeding: clinical outcomes in the medicine or surgery trial. Obstet Gynecol. 2004;104(4):864.

18. James A, Matchar DB, Myers ER. Testing for von Willebrand disease in women with menorrhagia: a systematic review. Obstet Gynecol. 2004;104(2):381-8.

19. Kouides PA. Obstetric and gynaecological aspects of von Willebrand disease. Best Pract Res Clin Haematol. 2001;14(2):381-99.

20. Knol HM, Kemperman RF, Kluin-Nelemans HC, Mulder AB, Meijer K. Haemostatic variables during normal menstrual cycle. A systematic review. Thromb Haemost. 2012;107(1):22-9.

21. Munro MG, Critchley HO, Broder MS, Fraser IS, Figo Working Group on Menstrual Disorders . FIGO classification system (PALM-COEIN) for causes of abnormal uterine bleeding in nongravid women of reproductive age. Int J Gynaecol Obstet. 2011;113(1):3-13.

22. Miller CH, Dilley A, Richardson L, Hooper WC, Evatt BL. Population differences in von Willebrand factor levels affect the diagnosis of von Willebrand disease in African-American women. Am J Hematol. 2001;67(2):125-9.

23. Weiss JA. Just heavy menses or something more? Raising awareness of von Willebrand disease. Am J Nurs. 2012;112(6):38-44.

24. Sanders S, Purcell S, Silva M, Palerme S, James P. Relationship between diagnosis and intervention in women with inherited bleeding disorders and menorrhagia. Haemophilia. 2012;18(3):e273-6.

25. Cohan N, Karimi M. Diagnosis and management of von Willebrand disease in Iran. Semin Thromb Hemost. 2011;37(5):602-6.

26. Boswell HB. The adolescent with menorrhagia: why, who, and how to evaluate for a bleeding disorder. J Pediatr Adolesc Gynecol. 2011;24(4):228-30.

27. Sadler JE. Von Willebrand disease type 1: a diagnosis in search of a disease. Blood. 2003;101(6):2089-93.

28. Stefanska E, Vertun-Baranowska B, Windyga J, Lopaciuk S. [Von Willebrand disease in women with menorrhagia]. Ginekol Pol. 2004;75(1):47-52

29. Janssen CA, Scholten PC, Heintz AP. A simple visual assessment technique to discriminate between menorrhagia and normal menstrual blood loss. Obstet Gynecol.1995;85(6):977-82.

30. Faranoush M, Danaei N, Ghorbani R, Rahamni M, Jazebi M, Shashaani T. Survey of the relationship between of thrombophilic factors and the rate and severity of bleeding in patients with severe hemophilia A. Koomesh. 2008;9(4(28)):329-36.

31. Faranoush M, Jafarpoor A, Ghorbani R, Rahmani M, Jazebi M, Shashaani T, et al. Correlation of thrombotic factor with bleeding severity in patient's with factor XI deficiency. Koomesh. 2009;11(1):Pe55-60. 